STUDIA UBB PSYCHOL.-PAED., LXVI, 1, 2021, p. 49 - 75

(Recommended Citation)

DOI:10.24193/subbpsyped.2021.1.03

\title{
A METHODOLOGICAL APPROACH TO THE INVESTIGATION OF LANGUAGE FLEXIBILITY IN PRESCHOOLERS: THE ROLE OF TOYS AND PARENTAL BELIEFS
}

\author{
ALEXANDRA MARIAN ${ }^{*}$, THEA IONESCU1, OANA BENGA1
}

\begin{abstract}
The aim of the present study was to investigate the influence of the toy-type and parental beliefs about play in the development and use of language in a flexible manner by preschool children. Namely, we defined language flexibility as the ability to use multiple labels for the same object, in response to a particular verbal context. Children's language flexibility was evaluated with a newly-designed task that comprised several story-like situations in which the main character needed the child's help to solve a problem.

The main results failed to prove a statistically significant difference between the two groups of children in the language flexibility task. But the performance on the language flexibility task was positively and significantly associated with some free time activities that children are frequently involved in and with parent's willingness to let their children play with a toy in a different way than its prescribed mode. In contrast, the frequency and time spent by the child watching TV or playing on the computer was negatively and significantly associated with the performance on the language flexibility task.

As a conclusion, we discussed the current results side by side with some proposals regarding both methodological improvements on the current experimental procedure and future research attempts at investigating language development and language flexibility of preschoolers.
\end{abstract}

Keywords: play, toy type, language flexibility, parental beliefs, preschoolers

1 Department of Psychology, Babes-Bolyai University, Cluj-Napoca, Romania

* Corresponding author: alexandramarian@psychology.ro 


\section{Introduction}

\section{Parent-child interactions during play: the importance of the distinction between simple and electronic toys}

Play is a central activity in the first years of life of a child, with major benefits for language development, self-regulation, symbolic thinking, and socio-emotional development (Healy \& Mendelsohn, 2019). Although what we call "play" has not changed that much over time, the category of "toy" has expanded very much over the last century. With respect to what we call "play" or "playful activity", the scientific literature offers a constant definition that includes bouts of interaction between two or more partners, interaction that is usually accompanied by different objects, linguistic utterances, gestures, and actions (Roopnarine, 2012). If we turn our focus towards the objects used in play interactions, namely toys, there is a number of scientific studies that offer a classification of toys, distinguishing between "traditional" or "simple toys", or in other cases, between "complex" or "electronic" toys (Healy \& Mendelsohn, 2019). Healy and Mendelsohn (2019) offer a taxonomical categorization for traditional toys. In their view, there are several categories in which toys can fit in. We can talk about toys that can serve symbolic or pretend play, toys that can aid gross/fine motor skill progress, or toys that can foster language development. On the other hand, electronic toys usually mean just battery toys (that have lights and make sounds, that can move, etc.) and are a distinct category from video games and other screen devices (Healy \& Mendelsohn, 2019).

From an intuitive perspective, we can infer that the toys with which children play in their first years of life influence and contribute to their cognitive and socio-emotional development. In this direction, there are several studies focusing on the impact of the toy type used in play interactions on the dynamics of social exchange between play partners. Some toys inflict a more directive approach to play (e.g., playing with Legos), whereas others encourage frequent naming of objects or addressing questions (e.g., playing with dolls) or using more sounds than words (e.g., playing with cars) (O'Brien\& Nagle, 1987). There are also studies that show that preschool children can adjust their pattern of play interaction depending on the play partner (Leaper \& Gleason, 1996). More recent studies have also focused on how electronic toys mediate both the interaction with the play partner and the cognitive and socio-emotional development of infants and preschoolers (Miller, Lossia, Suarez-Rivera, \& Gros-Louis, 2017). The interest in how electronic toys shape the play activities and further, the development of children, is supported by the abundance of these toys which are 
A METHODOLOGICAL APPROACH TO THE INVESTIGATION OF LANGUAGE FLEXIBILITY IN PRESCHOOLERS: THE ROLE OF TOYS AND PARENTAL BELIEFS

usually presented under the label of "educational toys". Some of these toys are claimed to have certain characteristics that support language development and other cognitive abilities of infants and preschoolers (Sosa, 2016).

Despite their wide production and support from social media advertisers, there is no clear picture of how certain features of electronic toys (sounds, music, etc.) influence the dynamics of parent-child play interactions (joint attention episodes, linguistic utterances, the direction and frequency of episodic interaction, etc.) and children's cognitive and socio-emotional development (Zosh, Verdine, Filipowicz, Michnick Golinkoff, Hirsh-Pasek, \& Newcombe, 2015). Zosh et al. (2015) showed that when electronic toys are used during parent-child play episodes, the quality - but not the quantity - of the spoken language produced by the parent is affected. Moreover, Woolridge and Shapka (2012) have also shown that the quality of the parent-child interactions (e.g., the degree of parental contingency and responsiveness during episodes of play, frequency of verbal utterances) during play instances is affected when electronic toys are used: mothers are less responsive, offer fewer explanations and ask fewer questions. Also, when the same type of toys is used during play, mothers are less supportive of the child (they are more directive and give the child fewer chances to explore the toys) (Woolridge \& Shapka, 2012). Sosa (2016) has also investigated the quality and quantity of parent-child communication during play, while interacting with two types of toys: traditional (objects that encourage more free play such as puzzles, chunks of wood) and electronic (objects that operate via batteries and have buttons or make sounds) and also storybooks for children. The results have shown that the interaction was most negatively affected when the play interaction was mediated by electronic toys; the story books for children were associated with the greatest number of vocalizations both from the child and the parent (Sosa, 2016). In the same line, Clemens and Kegel (2020) have shown that as early as the first year of life, shared book reading is the most powerful tool in stimulation language development for the child. Furthermore, Miller et al. (2017) have confirmed the results of the previous studies that have looked at how the quality and quantity of communication during play is influenced by the type of toys used (traditional toys vs. toys that offer feedback). Moreover, the researchers have shown that the type of toys used during play can impact upon certain cognitive measures: the children involved in this research have manifested stronger sustained attention while interacting with toys that offered feedback, than while playing with the more traditional toys. A possible explanation for these results could be found in the novelty factor offered by the sounds and movements featured by the toys that offer feedback. Also, during play with traditional toys, parents more often reoriented the attention of their children, a behavior that can interfere with a 
longer, uninterrupted interaction with a toy (Miller et al., 2017). More recent studies that have looked into how digital versus non-digital toy play can impact on the quantity and quality of children's speech have also taken into consideration the parental factor: whether parental intervention during play matters to the language development process of the child. Ewin, Reupert, McLean and Ewen (2021) have shown that children's language development benefits most when they engaged with their parents in non-digital play because this type of context prompted parents to talk more with their children. Interestingly, joint media engagement with the parent can also benefit the child in developing his vocabulary, given that the parent constantly interacts with him.

Drawing from the results of the studies mentioned above, we can conclude that parent-child interactions during play with electronic toys differ from playing interactions that include traditional toys on certain parameters (quality and quantity) of the communication process. Play episodes involving electronic toys result in fewer utterances from both the child and the parent, and less willingness to engage in symbolic play. Moreover, during play with electronic toys, parents tend to offer fewer contingent responses and elaborations pertinent to the play context and are more predisposed to initiate and direct the play interaction.

\section{Parental attitudes and beliefs towards play}

Scientific studies show that parents orient their child's rearing, and they structure childhood activities based on their belief systems. These beliefs often tell them when and how children acquire common developmental tasks or how they should interact with their children in accord with a given developmental phase in their lives (Parmar, Harkness, \& Super, 20040. Moreover, these theories that parents hold about child rearing have been shown to influence the organization of their children's environments of learning and development (Taggart, Becker, Rauen, Kallas \& Lillard, 2020; Ban \& Uchiyama, 2020). For example, one study has shown that Euro-American parents who appreciated play for its educational and cognitive benefits, were more likely to join their children in play and to provide encouragement and support in pretend play, for example. On the other hand, Asian parents who viewed children's play as just for amusement and almost not at all important in preparing their children for entering school, did not tend to engage that much with their children during play (Parmar et al., 2004; Roopnarine, 2010).

It is already settled that play is a universal activity among young children, but studies show that its nature varies across cultures in response to specific constraints and differential degrees of encouragement. Most studies that have investigated parent's beliefs (mostly mother's belief systems) about play seem to 
A METHODOLOGICAL APPROACH TO THE INVESTIGATION OF LANGUAGE FLEXIBILITY IN PRESCHOOLERS: THE ROLE OF TOYS AND PARENTAL BELIEFS

fall along a continuum - from views about play as a central activity fostering cognitive and social development to beliefs of play as peripheral to childhood development (Parmar et al., 2004). Generally, in agricultural countries, with closeknit interdependent social ties, parents see play as not so much a mechanism through which children can develop early skills and competences, but an activity intrinsic to the child, almost automatic; therefore, the parent's partnership and guiding role is less important. On the other hand, in Western technologically developed societies, parent-child interactions during play contain more language, gestures and might contribute more and in unique ways to language and cognitive development. Specifically, joint-coordinated play activities between parents and children in the technologically developed societies are more likely to co-occur with objects and to involve labeling, gesture and motion and have thus been related to better language skills (Parmar et al., 2004).

Corroborating these findings, we can assert that during infancy and preschool years, play is a frequent activity in children's daily routines, with important contributions to the cognitive and socio-emotional development. Also, play is culturally situated in the familial and social experiences of the child, often reflecting the values within a specific cultural community. At this age, parents, close relatives, and peers are typically children's play partners. In Western and other technologically developed societies, play is valued for its role in the growth of cognitive and social skills. Therefore, parents from these cultures adopt an active role in play, by initiating meaningful interactions, by offering guidance, support, and contingent responses during play. Because parent's beliefs about play seem to influence their involvement (both qualitatively and quantitatively) within bouts of play interactions with their children, one should expect that the same child-rearing theories should also influence the play activities and what toys parents choose to be appropriate for their children (Liu, Escudero, Quattropani \& Robbins, 2020). For example, in their study, Kollmayer, Schultes, Schrober, Hodosi and Spiel (2018) have shown that parents' beliefs about whether there are toys that are suitable only for children and only for girls influence their ratings. with regards to the suitability of a set of toys to be used in play with their children. Specifically, parents with traditional gender-role attitudes consider crossgendered-typed toys to be less desirable for their children's play, than gender neutral toys, whereas parents with egalitarian gender role attitudes found crossgendered-typed toys as more desirable for their children. Also, the study has shown that egalitarian parents permit a wider range of interests and behaviors in their children, compared to traditional parents, by creating a less stereotypical environment for their children (Kollmayer et al., 2018).

Our sample of participants belongs to an Eastern-European society. To our knowledge, there are no studies looking into how these theories that parents hold about the role of play and toys in the cognitive and social development of their 
children, can influence their view about their role as a parent in play, the play activities and the toys chosen for their children. Therefore, for the purpose of our research, we believe it is important to take this factor into consideration and see whether it contributes to the language flexibility performance at the preschool age.

\section{Language development and language flexibility at preschool age}

For the current study, we subsume language flexibility to the broader concept of cognitive flexibility as a property of the cognitive system (Deak, 2003; Ionescu, 2012). Deak (2003) defines cognitive flexibility as the ability to build and dynamically change our behavior and representations of reality, in accordance with the linguistic and non-linguistic information coming from the environment. Consequently, we can state that language proves to be flexible when it successfully manages to mediate the relation between the growing variability of the developmental experiences of a person and his/her changing conceptual and cognitive repertoire (Deak, 2003). So, it might be that through play and other relevant activities, children become more and more flexible in using language, depending on the context (Schaffer, 2009). The studies that have investigated how the type of toys children interact with during play shape their development have mainly focused on vocabulary aspects (i.e., quality and quantity) that are visible in play interactions between the child and the parent. But there are studies showing that, early on in their development, children reveal their ability to use language in a flexible manner. For example, studies show that by 12 months of age, children can map together similar sounds (Hollich, Hirsh-Pasek, \& Michnick Golinkoff, 2000). At 17 months of age, children can attribute to novel words different symbols: hand signs, nonverbal sounds, and pictograms (Namy, 2001). Also, Thom and Sandhofer (2009) have shown that 20-month-olds' that were trained to learn the labels of multiple examples of a category (colors) managed to have a superior performance at learning and extending new labels, than children who simply saw instances of color. By 2 years of age, children prove a strong preference for words as a symbolic form and they do not choose a hand gesture or a sound as a symbol for a novel object (Woodward \& Hoyne, 1999; Namy \& Waxman, 1998; Namy, Campbell, \& Tomasello, 2004). Their language flexibility "reappears" at the

preschool age and can be seen, for example, in the ease with which children can adapt their verbal discourse to an ongoing social context (Poole, Nunez, \& Warren, 2007). Studies that have looked at flexibility in early verb use (Naigles, Hoff, Vear, 2009), show us that children's ability to use verbs in a flexible manner depends on vocabulary growth. The authors used a diary method approach, in which mothers kept a record of their children's (aged between 16 
A METHODOLOGICAL APPROACH TO THE INVESTIGATION OF LANGUAGE FLEXIBILITY IN PRESCHOOLERS: THE ROLE OF TOYS AND PARENTAL BELIEFS

and 20 months) verb acquisition for a total of 12 months. The results showed that in the early period of verb-use, children used their verbs both to command and describe, about multiple persons/objects and to describe a variety of actions or outcomes (Naigles et al., 2009). Also, all children included in the study displayed semantic and syntactic flexibility before 24 months of age. Despite these results, questions remain as to when and how a child can extend a verb. For example, we know that first comes the ability of the child to extend a verb to another agent, and afterwards comes the ability to extend a certain verb to a different outcome/action (Naigles et al., 2009).

Most studies that have investigated the early development of language flexibility, had to use tasks or other methods (e.g., observational measures) borrowed from the study of categorization or other child development aspects. Therefore, the construction and validation of a task that taps into language flexibility at the preschool age would be a methodological addition, that will hopefully offer us an instrument to observe and measure language flexibility in this period. And this is especially important, because in the preschool years the child starts to familiarize with a more formal learning environment that provide him/her with multiple activities and contexts in which he/she is challenged to use language in a flexible manner.

\section{The current study - outline and main objectives}

Previous studies that have focused on the role of toy-type on the dynamic interaction between play partners have almost exclusively looked at the quality and quantity aspects of vocabulary displayed by parents and children during play. Although Miller et al (2017) found some implications of the toys used during play on cognitive development (i.e., sustained attention), there are not many studies that sought to investigate in depth the impact of contextual factors on cognitive development. Also, previous studies have taken into consideration the role of parental theories about play and toys' benefits to child development, but mainly from a culturally focused approach (Roopnarine, 2010; Parmar et al., 2004). Also, they have not looked so much at how these beliefs shape parents' actions which are further reflected in their children' proximal environment.

Deriving from this, the current study aims to investigate whether the type of toy with which preschool children (3-4year-olds) interact during play with a partner (i.e., the experimenter), can have an influence on their language flexibility, evaluated with a language task developed and validated in a preliminary pilot study. And because language development and its flexible use - as every aspect of human development- is influenced by a dynamic interplay of internal 
and external factors, we also sought to investigate the role that parent's belief systems and the activities their children are involved in, can have a word into their language development.

As such, we hypothesized that in the language flexibility task, preschool children that interact with "simple toys" during play with an experimenter have a better performance than those children that play with "complex" toys. We also expect a higher performance in the task for those children who are constantly involved in more unstructured activities (that implicitly might require more verbal and nonverbal interactions between partners), and whose parents have a more relaxed and apprehensive approach to play and to the role of play activities for language development at the preschool age.

We first conducted the pilot study in which we sought to test validate the experimental task and make sure that it is appropriate to measure language flexibility in the age range included in our research. Specifically, the pilot study was used to verify if the toys (simple and complex) chosen by the researchers, and the flexibility task are suited for the preschool age. We will present first the pilot study and further on, we will describe the findings of the main study, in which we investigated if the toy type used in play interactions by preschool children can influence their performance in using language in a flexible manner (evaluated with the same language flexibility task as the one used in the pilot study).

Also, we considered the role of parental beliefs and activities that their children are regularly involved in, in the development of language flexibility. Finally, we concluded with a general discussion about the results and their implications for language flexibility development at an early age.

\section{Pilot study}

\section{Method}

In the pilot study, all children interacted with both the simple and complex toys to see whether they recognize the toys, can interact with them and if the objects chosen by the experimenter can be easily used in a dyadic play interaction. Also, all children completed the language flexibility task, in their second encounter with the experimenter.

\section{Participants}

The participants were preschool children $(\mathrm{N}=18$, mean age $=40$ months, $\mathrm{SD}=6.88$ ), from a kindergarten from the city of Cluj-Napoca, in Cluj county, Romania. The initial study sample comprised 19 participants, but one participant 
A METHODOLOGICAL APPROACH TO THE INVESTIGATION OF LANGUAGE FLEXIBILITY IN PRESCHOOLERS: THE ROLE OF TOYS AND PARENTAL BELIEFS

refused to complete the language flexibility task, so he was excluded from the study. Only the children whose parents signed the informed consent were included in the study. After the completion of the pilot study, all children received a sticker, as a reward for their participation.

\section{Instruments}

\section{Toys}

The toys included in the study were chosen as to fit the simple and complex toys categories, namely simple and complex toys. In this study, we distinguished between "simple" and "complex" toys based on previous research on this topic (Zosh et al., 2015; Sosa, 2016; Miller et al., 2017; Healy \& Mendelsohn, 2019). Therefore, a "simple" toy is one that does not immediately imply a single mode of playing with it during the play activity (ex., play dough - can be used in several ways, such as creating animals, different objects, food dishes, etc.), whereas a "complex' toy has certain features that direct the play activity more overtly (e.g., a toy car can be used in a race, or to drive somebody with it). There were three toys for each of the two categories, so there was a total of six toys. The toys chosen for the study corresponded to three categories: animals, colors and geometrical figures, and there were two toys for each category (one simple, one complex) (see Appendix 1 for a description including pictures of the toys). We have chosen toys to match these three object categories for two reasons: 1) developmentally, it is likely that objects matching these categories are familiar to preschool children; 2) previous studies relevant for our research purpose have used two or three thematic categories, so as to balance the experience of the child with the stimuli in the experimental setting (avoiding the situation wherein a child plays with more simple or more electronic toys, or with more toys pertaining to a category than to another category).

\section{Language flexibility task}

To evaluate children's language flexibility, we developed a task that consisted in six short stories in which the participant is asked to name and use an object according to a new function ascribed by a current problem he is asked to help solving., and not according to the name and function he has for that object. The design of the task was inspired from tasks used in studies that assess flexible categorization in preschoolers and that usually seek to prove if children can use more linguistic labels for the same object. Each story had a main character that needed help from the child to solve a critical problem. The stories were presented to the child on laminated cards (three cards for each story). The cards contained original drawings made by the first author and were presented 
in the chronological order of the plot. For each story, the "help" offered by the child consisted in choosing - from a set of three cards picturing different objects one, two or all three of them, that would replace a typical solution (the target word) from the story and solve a critical problem. For example, in the first story, the child must replace a broken vase (here, the typical solution) by choosing between a ball, a cup and a boot. (the complete story can be found in Appendix 2). The three cards chosen for each story, comprised objects ranked after the similarity (of shape or function to the target-word). Therefore, there was a closely associated and a remotely associated object to the target-word, and a distractor. This distinction (closely vs. remotely associated to the target-word) was made based on a ranking-task given to 20 adults (16 females and 4 males, mean age $=26$ years). They were given an answering sheet that could be completed online or by paper and pencil, wherein they had to read a set of target-words. For each of these words, they were given several words (e.g.: a cup, a boot, and a ball) that they had to rank based on their closeness (function or shape) to a targetword (e.g.: a vase). For each group of three/four words, a word was given the highest rank when it was voted closest to the target-word by most participants. The word that received the fewest votes from the participants was considered the distractor, whereas the remotely associated word was the one whose ranking laid between the closely- associated word and the distractor word. Because the purpose of the pilot study was to verify the appropriateness of the toys chosen for the play interactions and the task developed, the performance of the children was evaluated using an answering sheet wherein the experimenter recorded the child's choice/es of objects for each story. For the statistical analysis, every chosen object received a numerical value of "1" and every object that was not opted for received a value of " 0 ". This permitted us to perform a frequency analysis that checked into the percentage and the number of children who chose every object for all six short stories from the language flexibility task.

\section{Procedure}

Each child participated in two sessions of play with the experimenter, in a quiet room in the kindergarten. Between the play sessions there was a maximum 4-day lag, to prevent the children from remembering the toys and their features. In the first play session, each child interacted with all six toys, for approximately 15 minutes. The child was encouraged to manipulate and explore the toys and received contingent feedback whenever necessary: the experimenter responded promptly to the questions, actions, or the requests of the child during the play interaction, whenever was the case. In the second session (that lasted about 25 minutes), the child interacted again with the same 
A METHODOLOGICAL APPROACH TO THE INVESTIGATION OF LANGUAGE FLEXIBILITY IN PRESCHOOLERS: THE ROLE OF TOYS AND PARENTAL BELIEFS

six toys from the first session, and afterwards he was tested with the language flexibility task. Each child was presented in succession with all of the six short stories. For instance, in one of the short stories, the child is being told that Ann is a smart and well-behaved girl that went to visit her grandmother. One morning, Ann goes out in her grandmother's garden and notices all the beautiful flowers surrounding the house. She picks up some to form a bouquet and ran into the kitchen to find a vase. Because she is very excited to surprise her grandmother, she breaks the only vase that her grandmother has (in this case, the target-object was the vase). At this point in the story, the child is asked to help Ann find another vase for the flowers and he is shown three cards picturing three distinct objects: a closely associated object (in this case, a cup), a remotely associated one (a boot) and a distractor (a tennis ball). The experimenter tells the child to offer him a "vase" and writes down (on the evaluation sheet) the child's choice/choices. Also, to make sure the children knew what the objects on the cards were, the experimenter asked the children to name the object on each card. This was required because, if the label for an object is not acquired, we cannot talk anymore about language flexibility. Flexibility in this case meant that the child was capable to find another object for the problem and offer this another label, appropriate to the particular context. With regards to the rating of the children's performance in the task, for each of the six stories, every child received a numerical value of " 0 " if he did not choose any object or if he chose the distractor. Further, each child received a numerical value of " 1 " if he chose either one of the three objects but the distractor, and a value of " 2 " if he chose both the closely related and the remotely related objects, but not the distractor. Based on this algorithm, each child received a "flexibility score" at the task, in which we added the number of stories wherein the participants showed maximum flexibility - they opted only for the closely-related and the remotelyrelated objects. We considered a child to be "linguistically flexible" only if he obtained a score of " 2 " at a minimum of 4 stories (the minimum flexibility score could be 8 and the maximum, 12).

\section{Results}

Because the purpose of the study was to verify the appropriateness of the toys and of the language flexibility task for the target age range, we did not split the children into groups based on the type of toys. Therefore, at this level, we only observed that the toys chosen for the study were appropriate: the children showed interest when engaging with them and they were willing to share the toys with the experimenter. Most children remembered the toys from one encounter to another, but that did not constitute an impediment to the study (they did not seem bored or unwilling to play). We decided to replace only 
one toy (the animal origami), due to children's difficulty in playing with it: except from one participant, the children could not follow the steps after which the pieces of paper had to be folded to obtain the correct animal. With respect to the performance on the language flexibility task, in general, most children opted for the closely related object as a first option to replace the target-word in each story. Only in Story 6 did the children opted equally often for the closely related and the remotely related option. Table 1 summarizes the responses of each child for the six short stories included in the task:

Table 1. Children's toy-choice percentage-response for the six stories

\begin{tabular}{cccc} 
Story & Answer options & Percentage & Number \\
\hline \multirow{3}{*}{ Story 1} & closely related & $100 \%$ & 18 \\
& remotely related & $28 \%$ & 5 \\
& distractor & $17 \%$ & 3 \\
\hline \multirow{3}{*}{ Story 2} & closely related & $61 \%$ & 11 \\
& remotely related & $44 \%$ & 8 \\
& distractor & $6 \%$ & 1 \\
\hline \multirow{2}{*}{ Story 3 } & closely related & $78 \%$ & 14 \\
& remotely related & $56 \%$ & 10 \\
& distractor & $17 \%$ & 3 \\
\hline \multirow{3}{*}{ Story 4} & closely related & $78 \%$ & 14 \\
& remotely related & $50 \%$ & 9 \\
\hline \multirow{2}{*}{ Story 5 } & distractor & $6 \%$ & 14 \\
& closely related & $78 \%$ & 8 \\
& remotely related & $44 \%$ & 5 \\
\hline \multirow{2}{*}{ Story 6} & distractor & $28 \%$ & 14 \\
& closely related & $78 \%$ & 14 \\
\hline
\end{tabular}

\section{Discussion}

For this study, we concluded that most of the toys were suited for the developmental age of the children. The participants could easily engage with the toys, both alone and in interaction with the experimenter and they manifested interest when playing with them. We decided to replace only one toy: the animal origami, because almost all (except one) of the children could not fold the papers correctly, to obtain the animals. Regarding the language flexibility task, the stories were easy to comprehend by the children and they were not too long for their age: except from one participant, every child managed to follow the plots of the stories and to give an answer at the end of each one of them. Because another goal of the study was to verify children's vocabulary knowledge of the 
A METHODOLOGICAL APPROACH TO THE INVESTIGATION OF LANGUAGE FLEXIBILITY IN PRESCHOOLERS: THE ROLE OF TOYS AND PARENTAL BELIEFS

objects pictured on the small cards, we decided to eliminate those pictures of the objects that were not recognized by most of the children (badge, paperclip, necklace, closed book). The final cards used in the main study are shown in Appendix 2. Regarding children's performance at the language flexibility task, a frequency analysis computed for each story showed us that for the most stories, children often chose the closely associated object to replace the targetword. The only exception was story number 6 , where the remotely associated object (the orange) was chosen equally often as the closely associated one (the thread ball). The distractor in each story was rarely chosen as a viable option to replace the target-word. Only in Story 3 and Story 5, the distractor was chosen more than 1 time ( 3 times and 5 times, respectively). Even though for all the stories (except Story 6), the closely-related object was the preferred choice for all the children, we can observe from the data that they also chose the remotelyassociated object on quite a few occasions (more than $40 \%$ of the time for each story). This can offer us an idea about how language flexibility is manifested at this age when solving a verbal task.

\section{Main study}

The purpose of the study was to investigate the influence of toy type on preschool children's performance at a language flexibility task. We wanted to see if the children who interacted with the simple toys would prove to use language more flexibly than those that played with the complex toys. A second purpose of our study was to investigate whether contextual factors such as parental attitudes and play activities can influence language flexibility development. Therefore, we collected self-report data from the parents regarding the play activities in which their children are involved and their parental attitudes towards the play activities of their children.

\section{Method}

We used an experimental design, with the type of toy (simple/complex) used in the play interactions as the independent variable, therefore resulting in two experimental groups: one group of children who interacted during the two play sessions with simple toys, and another one wherein the children played with complex toys. The dependent variable in the study was the performance at the language flexibility task. Because we wanted to obtain as much information about the contextual factors that influence the development of language flexibility at this age, we also obtained self-report data from the parents regarding the play activities in which their children are involved and their parental attitudes 
towards the play activities of their children. We used this data in a corollary analysis that verified if certain play activities or parental attitudes towards play are somehow related to the preschooler's ability to use their language in a flexible manner.

\section{Participants}

The participants of the study were preschool children $(\mathrm{N}=26$, mean age= 45 months, $\mathrm{SD}=4.88$ ) from a kindergarten from the city of Cluj-Napoca, in Cluj county. Initially, the experimental sample comprised 30 participants, but two of them dropped out due to medical problems, and the other two were excluded because they did not participate in the second play session (with the evaluation of the language flexibility). Only the children whose parents signed the informed consent were included in the study. The final sample of participants was divided in two groups, based on the toy-type used in the play interactions. Therefore, the "simple toys interaction" groups was comprised of 14 children, whereas the "complex toys interaction" group consisted of 12 participants. After the completion of the study, all children received a sticker as a reward.

\section{Instruments}

Toys

The toys included in the study were the same as those used in the pilot study, except for the animal origami, that was replaced by an animal domino game. Like for the pilot study, there were three toys for each of the two categories (see Appendix 1 for pictures of the toys and their description), so there was a total of six toys. The toys chosen for the study corresponded to three categories: animals, colors and shapes, and there were two toys for each category (one simple, one complex per category).

\section{Language flexibility task}

To evaluate children's language flexibility, we used the same task as the one described in the pilot study. The only difference was the cards replaced after the feedback received from the children included in the pilot study. A pictographic example of one story from the task can also be found in Appendix 1. The replacements are also listed in Appendix 2. With regards to the rating of the children's performance in the task.

\section{Self-report questionnaires for parents}

The parents who agreed with the participation of their children in the study completed two short questionnaires that were attached to the informed consent. The first questionnaire was taken from Woolridge and Shapka (2012) 
A METHODOLOGICAL APPROACH TO THE INVESTIGATION OF LANGUAGE FLEXIBILITY IN PRESCHOOLERS: THE ROLE OF TOYS AND PARENTAL BELIEFS

and it has eight items that evaluate the main play activities in which a preschool child can be involved (interaction with toys, children's books, screen time, physical playing activities, etc.) and the time spent doing those activities. The items are evaluated on a 7-point Likert scale (>1/day, 1/day, 3-4/week, 1/week, <1/week, sporadic, never). For each of the 8 items, the questionnaire also evaluates (on a 5-point Likert scale, < $5 \mathrm{~min}, 5-10 \mathrm{~min}, 10-20 \mathrm{~min}, 20-30 \mathrm{~min},>30 \mathrm{~min}$ ) the time spent doing those activities. Besides these items, the questionnaire has an item that evaluates the amount of electronic toys present in the household (on a 4-point Likert scale, none, a few, about half, most, almost all) and another item that evaluates the importance that parents place on play, as an activity. Moreover, the questionnaire has an item that evaluates the main play partners of the child. For this questionnaire, we calculated the frequency and the average time the children spend in various play activities. Besides this questionnaire, the parents also filled a short questionnaire (three items, on a 5-point Likert scale) that evaluates parent's attitudes towards their children's play interactions ("I agree that my child plays with an object/toy in a different manner than the one that is socially approved or suggested in the instructions"; "I encourage my child to include objects from the household - other than toys - in his playing activities", "I agree when my child chooses to interact during play with toys that are thematically unmatched or toys that differ one from another in terms of way of interaction - for example, your child decides to imagine a play plot in which he/she includes farm animals and toys that are usually used at the sand pit'). For each of these items, we calculated the frequency with which parents agree with either of the statements.

\section{Procedure}

The procedure was the same as the one followed in the pilot study. The only additional feature was that every interaction with the child was videorecorded and the child interacted only with three toys per play session, according to the condition that the child belonged to. The testing procedure was the same as the one used in the pilot study, after the experimenter obtained the informed consents and the self-reported questionnaires from the parents. At the end of the testing, each child from the two groups (including those children that did not participate in the study) received a sticker as a reward.

\section{Results}

Performance at the language flexibility task

To see if there were any differences between the two groups at the language flexibility task, given by the toy condition, we computed a MannWhitney U test, a nonparametrically statistical test that is used to compare unpaired groups. The results of the study have shown that there was no 
statistical difference between the two groups (simple toys vs. complex toys), for all three types of relatedness of the word to the target-word (closely related, remotely related or the distractor), in all six stories. That is, the type of toy with which the children interacted did not result in a tendency to choose more often both the closely related and the remotely related pictures, as we have expected for the simple toys group. We further compared the performance of the two groups at the language flexibility task by computing the frequencies with which the children showed flexibility at the language flexibility task. The results have shown that in the "simple toys" play interaction group ( $\mathrm{N}=14$ children), 4 children (29\%) did not show language flexibility in the task, 5 children (39\%) showed flexibility at one of the stories in the task, 1 child (7\%) showed flexibility at 2 stories, 3 children (21\%) showed flexibility at three stories and only one child $(7 \%)$ proved to have flexible performance at all six stories. For the complex toys play interaction group, the frequency analysis has shown that out of 12 children, three (25\%) did not manifest language flexibility in the task. Two children (17\%) manifested flexibility at one story from the task, 3 children $(25 \%)$ showed flexibility at two stories, 2 children (17\%) showed flexibility at five stories and two children (17\%) proved to be flexible at all six stories comprised in the task. The results are summarized in Table 2:

\begin{tabular}{ccc} 
Group & Number of stories & $\begin{array}{c}\text { Number and percentage of } \\
\text { children who proved } \\
\text { language flexibility }\end{array}$ \\
\hline Simple toys interaction & no stories & $4(29 \%)$ \\
$\mathbf{N = 1 4}$ & 1 story & $5(36 \%)$ \\
& 2 stories & $1(7.1 \%)$ \\
& 3 stories & $3(21 \%)$ \\
Complex toys interaction & all stories & $1(7.1 \%)$ \\
$\mathbf{N = 1 2}$ & no stories & $3(25 \%)$ \\
& 1 story & $2(16.7 \%)$ \\
& 2 stories & $3(25 \%)$ \\
& 5 stories & $2(16.7 \%)$ \\
\hline
\end{tabular}

Because for this age the coding procedure might have been too "strict", we reconsidered it and we decided to recalculate the $U$ test and frequency analysis. This time, we considered that a child prove language flexibility if he chose either one of the closely or remotely related objects as replacement for the target-word. After this modification, the Mann-Whitney U test still showed 
A METHODOLOGICAL APPROACH TO THE INVESTIGATION OF LANGUAGE FLEXIBILITY IN PRESCHOOLERS: THE ROLE OF TOYS AND PARENTAL BELIEFS

no statistical difference between the two groups (simple toys vs. complex toys), for all three types of relatedness of the word to the target-word (closely related, remotely related or the distractor), in all six stories. As for the frequency analysis, we saw that in the "simple toys" interaction group, four of the children (28.6\%) have shown language flexibility at three stories, three children $(21.4 \%)$ have shown language flexibility at four stories, and six children (42.9\%) have proven to be flexible at all the six stories. As for the "complex toys" play interaction group, three children (25\%) have shown language flexibility at the task at three stories, one child (8.3\%) has shown language flexibility at four stories, four children (33.3\%) have shown language flexibility at five stories, whereas four children (33.3\%) have shown language flexibility at all the six stories. The results are summarized in Table 3:

\begin{tabular}{ccc} 
Group & Number of stories & $\begin{array}{c}\text { Number and percentage of } \\
\text { children who proved } \\
\text { language flexibility }\end{array}$ \\
\hline Simple toys interaction & 0 stories & $1(7.1 \%)$ \\
$\mathbf{N}=\mathbf{1 4}$ & 3 stories & $4(28.6 \%)$ \\
& 4 stories & $3(21.4 \%)$ \\
Complex toys interaction & all stories & $6(42.9 \%)$ \\
$\mathbf{N}=\mathbf{1 2}$ & 3 stories & $3(25 \%)$ \\
& 4 stories & $1(8.3 \%)$ \\
& 5 stories & $4(33.3 \%)$ \\
\hline
\end{tabular}

\section{Self-reported data}

For the questionnaire regarding the play activities of the child, most parents reported (68\%) to have only a few electronic toys in the household, and some of them $(20 \%)$ reported that half of the toys their children play with are electronic/with batteries ( $\mathrm{M}=2.44, \mathrm{SD}=0.71)$. Also, all parents considered play to be important for their child's cognitive and socio-emotional development. Regarding the most common play partners of the child, their parents were the most frequent response (53\%), followed by siblings (20\%) and friends (16\%), and ultimately caregivers $(11 \%)$.

Parents also reported the frequency and time spent by their children in seven different types of play. Therefore, on average, parents reported that their children interact with their toys at least once a day, for at least 20-30 minutes. Also, children in this sample interact with children's books/reading materials at least once a day, for about 20-30 minutes and engage in language games 3-4 
times per week, for about 10-20 minutes. Parents reported that their children spend time watching TV/ other screen media on an average of once a day, for about 20-30 minutes and participate in household activities (e.g., setting the table) 3-4 times a week, for about 20-30 minutes. Finally, parents reported that their children engage in physical play at least once a day, on an average of 2030 minutes and they go in excursions/walks less that once a week for an average of at least 30 minutes. The average frequencies and time spent in all seven play modes are summarized in Figure 1, below:

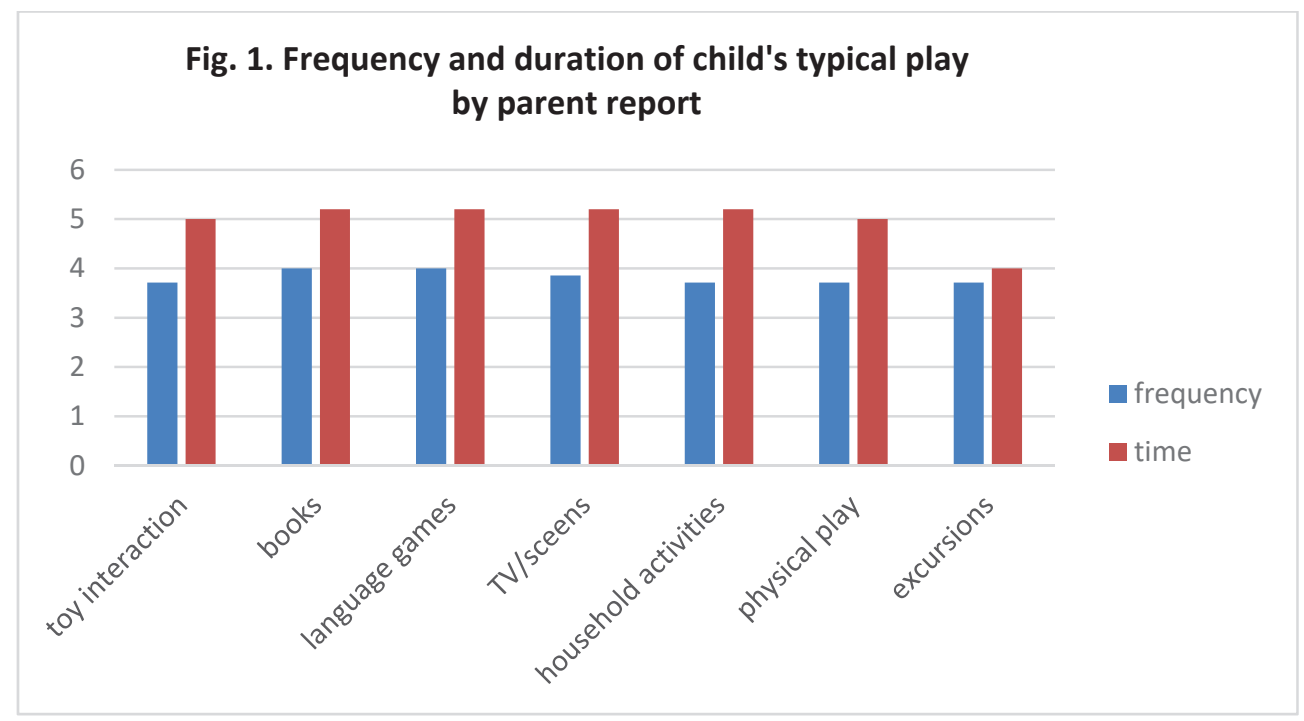

*Frequency $(0=$ never, $1=$ sporadic, $2=<1 / w k, 3=1 / w k, 4=3$ or $4 / w k, 5=1 /$ day, $6=>1 /$ day $)$

*Time/Play duration average in minutes $(1=<5,2=5-10,3=10-20,4=20-30,5=>30)$

We also analyzed the data from the parental attitudes towards their children's play interactions and we found out that, on average, parents totally $(44 \%)$ or partially agree (36\%) to accept and encourage their children to play differently with a toy (not according to predefined rules of play). Also, most parents $(72 \%)$ are willing to let their children play with objects that are not usually designed or considered to be suited for use in play activities (e.g., cutlery items, knick-knacks, etc.), whereas 16 percent strongly disagree to do so. Also, parents reported in $76 \%$ of the cases that they would let their children use during play toys that differ under certain aspects: type of interaction, category (e.g., a child that decides to include in a play episode farm animals and items used at the sand pit) and only $16 \%$ percent of the parents partially agree with this practice. 


\section{A METHODOLOGICAL APPROACH TO THE INVESTIGATION OF LANGUAGE FLEXIBILITY IN PRESCHOOLERS: THE ROLE OF TOYS AND PARENTAL BELIEFS}

Moreover, a one-way between subjects ANCOVA analysis was calculated with the responses of the two questionnaires as covariates, to see if the lack of differences between the two groups in terms of language flexibility performance is maintained, after we controlled for the effects of the parental attitudes towards play and the regular play activities that the children are involved in. The results supported the main result of the study, showing no influence of the toy type (independent variable) on the performance at the language flexibility task, after eliminating the effects of the play activities the children are generally involved and the parental attitudes towards play. Nevertheless, there were a few exceptions showing that the time spent by the child in interaction with reading materials is significantly and positively related to language flexibility, $F(1,21)=7.437, p=.029$. Also, the frequency and time spent watching TV or playing the computer was significantly, but negatively related to language flexibility, $F(1,21)=7.900, p=.026$ and $F(1,21)=5.286$, $\mathrm{p}=.05$, respectively. Finally, the time spent by the child helping their parents at household activities was significantly and positively related to the performance in the language flexibility task, $F=5.563, p=.05$. Regarding the importance of parental attitudes towards their children's play activities, we found that parent's consent in allowing their children to play with a toy in a different way than its default mode was significantly and positively related to language flexibility, $\mathrm{F}=5.007, \mathrm{p}=.03$.

\section{Discussion}

The purpose of the main study was to see if the type of toy the children interacted with in two play sessions can have an impact on their performance in a language flexibility task. The results failed to show any difference in language flexibility performance between the children who played with simple toys vs. the children who interacted with complex toys. Although the children managed to choose the closely related object to replace the target one at almost all occasions, they did not manage to go further and ascribe the target object's label to the remotely related object. Or they did, but not in a constant manner: only one child from the simple toys condition and two children from the complex toys condition managed to show language flexibility in all six stories present in the task. Also, the ANCOVA analysis did not show any change in the results after we controlled for the effects of the parental attitudes towards play and the play activities in which children are involved on a regular basis. Nevertheless, we observed that some play activities that the children are involved in are positively and significantly related to language flexibility, such as the time spent by the child reading children's books or other age-appropriate reading materials. This can be related to other relevant results that found a 
positive link between young children's interaction with children's books and aspects of vocabulary development (quality and quantity) (Sosa et al., 2016). Maybe while involved in reading a book, both the child and the parent have multiple opportunities to talk about different concepts and how they relate to each other and to other concepts or context wherein they can appear. Moreover, language flexibility was also associated with the frequency and time spent watching TV and other media and with the time spent helping parents at household activities. Regarding the relevance of certain parental attitudes towards play, we discovered that language flexibility was positively associated with parent's approval of their children to play with a toy in an unconventional way. Maybe if parents have a flexible approach not only in verbal interactions with their child, but also indirectly, in certain learning contexts, children might feel more encouraged to explore the environment.

\section{General discussion}

The general purpose of this paper was to propose an alternative approach on how to investigate language flexibility in preschool years, taking into consideration two contextual factors that might influence vocabulary development and its flexible use in different verbal interactions. We sought to see if the type of toy that preschool children use during play interactions can have an influence on their ability to use language flexibly in an experimental task. For this purpose, we developed a language flexibility task, that requires the child to adapt existent verbal labels in his vocabulary to a specific linguistic context. Therefore, our research had a methodological purpose, in which we tested if the task we have built is suitable for evaluating language flexibility for this age range. So, the first part of the research presented the piloting of the toys and the experimental task that was later used in the main experimental study. From the pilot study, we concluded that the toys were easy to play with, either alone or in interaction with the experimenter. The stories contained in the language flexibility task proved to be easy to understand and almost all children managed to follow the rationale of the task (choosing one or more cards with objects that could replace the target object).

As regards to the main study, we did not find an influence of the toy type on preschooler's performance in a language flexibility task. This might be because the children interacted with the toys only two times, or because the interaction lag was too big. Although almost all children managed to identify the closely related object as fit to replace the target one, most of the time they chose to consider the remotely-related object, therefore failing to show language 
A METHODOLOGICAL APPROACH TO THE INVESTIGATION OF LANGUAGE FLEXIBILITY IN PRESCHOOLERS: THE ROLE OF TOYS AND PARENTAL BELIEFS

flexibility, as it was defined in this study. This might be because the children's vocabulary at this age is still expanding, and they are not yet able to integrate fully the linguistic label of an object with its appearance and function. Therefore, they might succeed to use language flexibly in easier contexts, wherein these connections are more transparent, but encounter difficulties when that must use their language at a more abstract level. Also, the lack of difference in performance at the language flexibility task might be attributed to the task because it might have appeared a bit "artificial" to the children. Therefore, their lack of flexibility might be a result of a lack of understanding on "what it is requested from them" in a task that might look like a card game, and not come from a lack of ability.

Besides the role of the toy type in shaping the language flexibility performance of the children included in this study, we wanted to see if certain beliefs and practices that parents might have about play and the play activities their children are involved in might have an impact on their language flexibility. We saw that the time spent by the child reading and helping their parents in the household was significantly and positively related to language flexibility, whereas the frequency and time spent watching TV or playing the computer was significantly and negatively related to language flexibility. Moreover, it seems that the more open the parents prove to be when shaping the rearing environment of the child, the more children use their vocabulary in a flexible manner. These data prove that there is a complex interplay of factors that shape how children's vocabulary develops and reaches a flexible state at the preschool age.

The present study is not without limitations. First, we did not test the children with the language flexibility task before the play sessions, only after the second meeting, therefore we cannot state that the differences in performance (if there are any) are given by the toys that the children interacted with. Another limit might be the fact that we did not compare the two group's performance while the children interacted with different play partners (e.g., parents vs. experimenter). When engaging with a parent, the child might be more willing to interact and to produce more utterances, maybe leading to a better performance at a linguistic task. There are studies that have shown that engaging with the parent in dialogic reading (using prompting and questioning more often) resulted in a raised performance in children at vocabulary tests and also in an improvement in expressive language skills (Parish-Morris et al., 2013). Maybe a similar effect could be observed in playing interactions, independent of the toy used.

Another limit of the current research might be the small sample included in the main study. Maybe a bigger sample would have made visible a possible effect of the type of toy on children's performance at the language flexibility task. Also, the task might have been a bit different to the natural contexts in which 
children at this age are seen to manifest language flexibility. The children had to listen to a story and then chose from three images of objects printed on cards. This is a bit unusual for their age, although studies on categorization have proven that real, palpable objects (as compared to cards depicting those objects) do not make any difference in performance. Furthermore, apart from the characteristics of the task and its procedure, we might also add that children's performance in the pilot study was not compared with their performance in other tasks that measure language or flexibility in other domains, such as categorization. If done so, maybe we could have adjusted the task in a more suitable way that could assure a better evaluation of language flexibility in preschool children.

Also, future studies could investigate if play interactions with different partners (i.e., parents, siblings, or other caregivers) can result in different outcomes in terms of performance at the language flexibility task.

In conclusion, our study sought to investigate how language flexibility manifests at a preschool age and how can this ability be influenced by several contextual factors, here type of toys that children interact with and parental attitudes towards play. Therefore, we have built a new language flexibility task that we tested in two separate studies. The first one was a pilot study that sought to verify the toys' and task's appropriateness to children's developmental stage. In the second and main study, we applied the measurements (after proper adjustments) to a new sample of preschool children that were ascribed in two experimental groups, according to the toys they interacted with during the two sessions of play. According to the existent literature, play and toys are important factors that shape language development in early years. And recent studies have shown that the type of toys that children engage frequently during their play time can moderate the quantity and quality of communication between play partners (citation). Therefore, we went further to investigate if the type of toy can influence language flexibility performance in a task. Unfortunately, we did not manage to prove this hypothesis. But we did find out that language flexibility was positively associated with some other activities that children take part to frequently, such as reading books together with their parents or interacting with various social media sources Also, language flexibility was also positively associated with parent's openness and positive attitudes towards letting their children play with toys in a more unconventional way - not just according to play rules.

Although our study did not manage to prove that the type of toy that the child interacts with plays a part in language flexibility development at this age, we did point out the need to build new tasks to measure language development and flexibility in preschoolers. Also, we pointed out that there a more indirect factors at play for language flexibility development, such as parental attitudes towards play. The beliefs that we have regarding certain activities and practices 


\section{A METHODOLOGICAL APPROACH TO THE INVESTIGATION OF LANGUAGE FLEXIBILITY IN PRESCHOOLERS: THE ROLE OF TOYS AND PARENTAL BELIEFS}

can be flexible and can influence our parental decisions of, for example, the activities we decide for our children, or the time we spend in interaction with them. We do not yet know all the factors that influence language flexibility at this age and more importantly, we do not yet know how these factors interact to produce an outcome in a child's flexible use of his vocabulary. But what we do know is that an integrative approach is probably the best route to this discovery, an approach that better permits us to study language flexibility as a process.

\section{REFERENCES}

Ban, M., \& Uchiyama, I. (2020). Developmental changes in toy preferences during pretend play in toddlerhood. Early Child Development and Care, 1-10.

Clemens, L. F., \& Kegel, C. A. (2021). Unique contribution of shared book reading on adult-child language interaction. Journal of Child Language, 48(2), 373-386.

Deak, G. O. (2003). The development of cognitive flexibility and language abilities. Advances in child development and behavior, 31, 273-328.

Dore, R. A., Zosh, J. M., Hirsh-Pasek, K., \& Golinkoff, R. M. (2017). Plugging into word learning: the role of electronic toys and digital media in language development. In Cognitive Development in Digital Contexts (pp. 75-91). Academic Press

Ewin, C. A., Reupert, A., McLean, L. A., \& Ewin, C. J. (2021). Mobile devices compared to non-digital toy play: The impact of activity type on the quality and quantity of parent language. Computers in Human Behavior, 118, 106669.

Healey, A., \& Mendelsohn, A. (2019). Selecting appropriate toys for young children in the digital era. Pediatrics, 143(1), e20183348.

Hollich, G., Hirsh-Pasek, K., \& Golinkoff, R. M. (2000). I. What Does it Take to Learn a Word? Monographs of the society for research in child development, 65(3), 1-16.

Leaper, C., \& Gleason, J. B. (1996). The relationship of play activity and gender to parent and child sex-typed communication. International Journal of Behavioral Development, 19(4), 689-703.

Liu, L., Escudero, P., Quattropani, C., \& Robbins, R. A. (2020). Factors affecting infant toy preferences: Age, gender, experience, motor development, and parental attitude. Infancy, 25(5), 593-617.

Miller, J. L., Lossia, A., Suarez-Rivera, C., \& Gros-Louis, J. (2017). Toys that squeak: Toy type impacts quality and quantity of parent-child interactions. First Language, 37(6), 630-647.

Namy, L. L. (2001). What's in a name when it isn't a word? 17-month-olds' mapping of nonverbal symbols to object categories. Infancy, 2(1), 73-86.

Namy, L. L., \& Waxman, S. R. (1998). Words and gestures: Infants' interpretations of different forms of symbolic reference. Child development, 69(2), 295-308. 
Namy, L. L., Campbell, A. L., \& Tomasello, M. (2004). The changing role of iconicity in non-verbal symbol learning: A U-shaped trajectory in the acquisition of arbitrary gestures. Journal of Cognition and Development, 5(1), 37-57.

O'Brien, M., \& Nagle, K. J. (1987). Parents' speech to toddlers: The effect of play context. Journal of Child Language, 14(2), 269-279.

Poole, D. A., Nunez, N., \& Warren, A. (2007). The story of human development. Pearson/ Prentice Hall.

Sosa, A. V. (2016). Association of the type of toy used during play with the quantity and quality of parent-infant communication. JAMA pediatrics, 170(2), 132-137.

Taggart, J., Becker, I., Rauen, J., Al Kallas, H., \& Lillard, A. S. (2020). What Shall We Do: Pretend or Real? Preschoolers' Choices and Parents' Perceptions. Journal of Cognition and Development, 21(2), 261-281.

Thom, E. E., \& Sandhofer, C. M. (2009). More is more: the relationship between vocabulary size and word extension. Journal of Experimental Child Psychology, 104(4), 466-473

Thom, E. E., \& Sandhofer, C. M. (2014). How symbolic experience shapes children's symbolic flexibility. Child development, 85(2), 738-754.

Woodward, A., \& Hoyne, K. (1999). Infants' learning about words and sounds in relation to objects. Child development, 70(1), 65-77.

Wooldridge, M. B., \& Shapka, J. (2012). Playing with technology: Mother-toddler interaction scores lower during play with electronic toys. Journal of Applied Developmental Psychology, 33(5), 211-218.

Zosh, J. M., Verdine, B. N., Filipowicz, A., Golinkoff, R. M., Hirsh-Pasek, K., \& Newcombe, N. S. (2015). Talking shape: parental language with electronic versus traditional shape sorters. Mind, Brain, and Education, 9(3), 136-144. 


\section{Appendix 1 A}

\section{The toys used in the study:}

Animals:

- complex toy: a sensory mat with 6 animals and musical notes that made sounds when touched by the child or the experimenter.

- simple toy: a set of colored sheets of paper on which were drawn animals (a total of six animals) that the child had to fold by following certain steps, to obtain a certain origami in the shape of an animal.

Colors:

- complex toy: a set of puzzle cards that contained images of different objects/animals that had to be grouped together by color.

- simple toy: a set of play dough, with 12 colors.

Geometric figures:

- complex toy: a game called "Oaki knows everything", in which the child had to answer several questions listed in small cards by pressing with a frog-shaped pencil; and whenever the answer given was a correct one, the pencil would make a sound.

- simple toy: a set of geometric figures (sphere, triangle, square, cone) with magnets, which could be manipulated so as to build different constructions. 


\section{Appendix 1 B}

\section{Pictures of the toys:}

\section{SIMPLE TOYS}

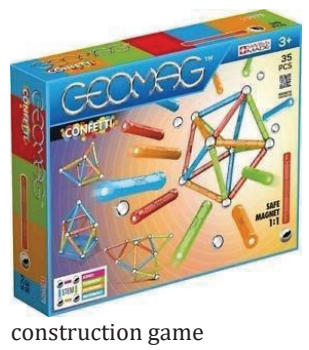

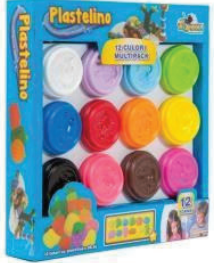

play-dough

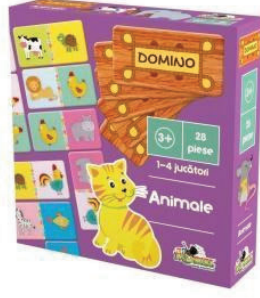

animal domino

\section{COMPLEX TOYS}
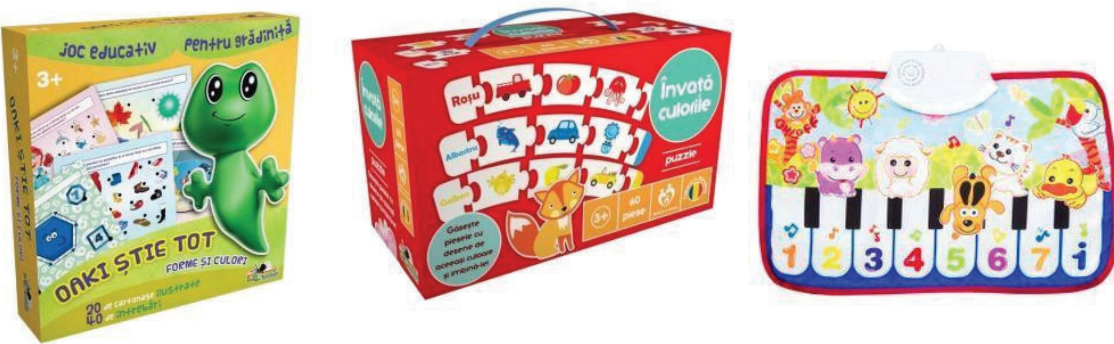

Oaki knows everything" color match puzzle animal learning mat

\section{TOY REMOVED AFTER PILOT STUDY}

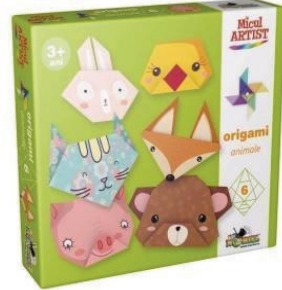

animal origami 
A METHODOLOGICAL APPROACH TO THE INVESTIGATION OF LANGUAGE FLEXIBILITY IN PRESCHOOLERS: THE ROLE OF TOYS AND PARENTAL BELIEFS

\section{Appendix 2 - Example of story used in the language flexibility task.}

\section{Story 1}

Ann is a smart and well-behaved girl that went to visit her grandmother. One morning, Ann goes out in her grandmother's garden and notices all the beautiful flowers surrounding the house. She picks up some to form a bouquet and ran into the kitchen to find a vase. Because she is very excited to surprise her grandmother, she accidentally broke the only vase that her grandmother has. Now Ann is very sad, because she thinks she ruined her grandmother's surprise and asked for our help. Let's find her a vase! Give me a vase? (in this case, the target-object is the vase)

The cards presented to the child for this story pictured:

Closely associated object: a cup

Remotely associated object: a boot

Distractor: a tennis ball 
